\title{
MJN VERBAL ABUSE IN THE WORKPLACE: THE UNFOLDING PHENOMENON
}

\author{
Jamichael-Almar E. Cabillo, Julius C. Daño* \\ Cebu Normal University, Philippines \\ *Corresponding Author's Email:juliuscoloniadano@gmail.com
}

\begin{abstract}
Violence in the workplace is a common situation among workers all over the world. This may happen to almost all companies and industries where violence is really a concern. One workplace where violence is rampant includes the hospitals and nursing homes. In the Philippines, nurses are confronted with physical, verbal, and emotional abuses. However, evidence of verbal abuse against nurses in the workplace are little and even fragmented literature reviews particularly on exposure rates, sources, and responses. This study determined the lived experiences of nurses who experienced verbal abuses in their workplace. The study utilized qualitative descriptive phenomenological approach that describe social phenomenon that is concerned with opinions, feelings and experiences of nurses as they occur naturally in the time of verbal abuse. Purposive sampling was used, and it focused on nurses who are employed in the hospitals. The instrument utilized the Bevans interview guide which is an essential concept to understand the present phenomenon. Descriptive bracketing allowed the researcher to focus on the pure essences of the phenomenon. The Colaizzi's eight steps were used in analyzing the data. The results of the study revealed the themes as result of their lived experiences. The first theme is destructive experience, the second theme is reactive responses, and the third theme is the evasive strategies. With these findings, the researcher noted the phases of the nurses lived experiences. Despite of difficulties, pain and sadness, the nurses have the capacity to resolve and cope any kinds of violent situations.
\end{abstract}

Keywords: Verbal Abuse, Nurses, Phenomenology, Bracketing

\section{INTRODUCTION}

Violence in the workplace is a common situation faced by workers all over the world. This may happen to almost all companies and industries where violence is a big concern. One workplace where violence is rampant includes the hospitals and nursing homes. It may also occur in other health care settings where the possible sources of violence are the people enjoying the services of the health professionals. Example of violence that happens in the workplace are verbal and physical attacks coming mostly from patients, co-workers like doctors, significant others who are distraught.

According to Anderson (2010), "workplace abuse and violence in health care settings, and against nurses, is a problem that is increasingly recognized at an internationally level. Workplace violence in health care settings, including hospitals, clinics and patients' homes, is a problem with profound implications for nurses' abilities to provide care effectively." The workplace violence has a deep rooted effect on the healthcare workers in recruitment and retention which is a matter of significance in a period of worldwide nursing shortages.

In the United States of America, physical and nonphysical workplace aggression causes a severe problem in the hospitals and other health care agencies. The Occupational Safety and Health Administration (OSHA, 2015) reported the largest source of verbal abuse in hospitals are the patients, followed by visitors and co-workers. The impact of verbal abuse may vary widely depending on the nature of the incident, the relationship between the victim and the abuser and the context in which it happened. The nature of verbal abuse may have consequences on physical, psychological and even social wellbeing of the victim (Jackson et al., 2013).

In the Philippines, 11,558 Filipino women between the ages of 15 and 49 suffered various forms of violence (Digal, 2018). In the healthcare setting like in the hospitals, healthcare professionals like doctors and nurses are also confronted with physical, verbal, and 
emotional abuses. These abuses are usually inflicted by patients and its significant others. One of the typical abuses Filipino nurses encounter every day in the workplace is verbal abuse. According to Philippine Statistic Authority (2017), they define verbal abuse as harsh and insulting language directed at a person resulting to loss of self-esteem and public dignity. Indeed, Filipino nurses suffer greatly on verbal abuse which harmed their dignity and self-esteem. However, what is important to note is that people who worked in high-risk occupations are vulnerable to verbal abuses and strategies to confront them physiologically and psychologically. This workplace verbal violence may lead to the awareness and decision of the victims about these transgressions and approaches to sustain it.

The present study was carried out in government tertiary hospital where yelling, screaming, shouting, intimidating and blaming is a normal scenario happening every day and most of the victims are the nurses. This verbal violence occurs in many areas especially in the Operating Rooms where almost everybody are behaving in this manner. These forms and acts of verbal abuse from patients, co-nurses, doctors and other allied medical practitioner is unfortunately a reality in the hospitals (Abdou \& El-Azeem, 2009) and these findings are also witnessed by the researcher. These verbal abuses are also extended from the patient and their family, co-nurses, nurse supervisors, senior nurses and even physicians to the nurses (Manderino \& Berkey, 1997). However, these verbal abuses in hospitals like Cebu City are not well reported and documented. Thus, the effects of verbal abuse among nurses in the Philippines are not well understood.

For nurses especially here in Cebu, Philippines, the verbal abuse is often difficult to distinguish. In the Philippine culture, most Filipinos don't take the abuses seriously and the feeling of pain are not immediately visible. The victim does not seek help because often they are used to being treated in a certain manner (Kvak, 2017). Verbal abuse in the workplace shows little and even fragmented qualitative literature reviews particularly on exposure rates and sources of verbal abuse. In trying to understand the phenomenon of verbal abuse of nurses, it is important to determine the lived experiences of nurses who really experienced this in their workplace. Thus, this study would like to explore the nurses' experiences of verbal abuses they encounter in their workplace.

\section{METHODOLOGY}

The study utilized qualitative research design specifically the descriptive phenomenological approach.
In qualitative research, it is used to describe social phenomenon that is concerned with opinions, feelings and experiences of the local population as they occur naturally that understanding was sought by taking a holistic approach.

Accordingly, the descriptive phenomenology was used, and it is an approach that concentrates on the study of consciousness and the objects of direct experience. This method allowed the nurses to express their own experience through interviews. As a result, the lived experiences of this verbally abused nurses were revealed (Varga \& Holloway, 2014; Al-Shamlan et al., 2017).

The descriptive phenomenology of Husserl's philosophy assume that experience as perceived by human consciousness has value and should be an object of scientific study (Qutoshi, 2018). It is the desire of the researcher to describe the lived experience of the verbally abused nurses in the workplace. The subjective information extracted from the key informants is very important in order to understand human motivation because human actions are influenced by what people perceive to be real.

\section{Research Locale}

This study was conducted in selected tertiary hospitals in Cebu City, Philippines. The study focused to one private and government owned hospitals. The private hospital has employed hundreds of nurses and worked in varied areas. They cater clients of different socioeconomic status in which majority of the patients are educated and financially able. Likewise, the government owned hospital has also employed hundreds of nurses working in many specialized areas. The clients and patients they cater are mostly indigenous group and the marginalized population.

\section{Research Informants and Sampling Technique}

The study utilized snowball purposive sampling in identifying prospective informants. It follows certain criteria in order to obtain a sample and this was grounded on the belief on the researcher's knowledge of the population (Tongco, 2007). The main objective of a purposive sample is to produce a sample that can be logically assumed to be representative of the population. In the search for prospective key informants, the snowball sampling was applied since the research key informants were difficult to find, in here the researcher asked the help of other colleagues to identify nurses who were victims of verbal abuse. They were made aware 
that they do not have to provide their names publicly so as to protect themselves from harm. The selection of nurses as the key informants in the study followed an inclusion criterion of being a registered nurse with experience of verbal abuses in the workplace. The exclusion criteria include informants experiencing other than verbal abuse.

The sample size generated in the study was five key informants and the researcher believed it reached a certain degree of saturation and the significant data generated were necessary for qualitative analysis (Creswell, 1998). The researcher noted that much of the information generated from the key informants were repeated and there was a point that the data gathered ensures the research question was answered. Thus, data saturation was reached. However, according to Patton (1990) "there are no specific rules what appropriate sample size in qualitative research, but the sample size may best be determined by the time allotted, resources available, and study objectives." The demographic profile of the key informants is tabulated on table 1 .

\section{Table 1: Demographic Information}

\begin{tabular}{|l|c|c|c|c|c|}
\hline $\begin{array}{l}\text { Key } \\
\text { Informants }\end{array}$ & Gender & Age & $\begin{array}{c}\text { Informant } \\
\text { Code }\end{array}$ & $\begin{array}{c}\text { Employment } \\
\text { Status }\end{array}$ & $\begin{array}{c}\text { No. of Years } \\
\text { employed }\end{array}$ \\
\hline Nurse 1 & M & 25 & 1 & Permanent & 2 \\
\hline Nurse 2 & F & 29 & 2 & Temporary & 1 \\
\hline Nurse 3 & F & 26 & 3 & Temporary & 3 \\
\hline Nurse 4 & F & 30 & 4 & Permanent & 7 \\
\hline Nurse 5 & F & 23 & 5 & Temporary & 1 \\
\hline
\end{tabular}

According to the table, there are five key informants among which one male and the four are females. They vary in terms of employment status were two of them holds a permanent position. This means their tenure ship is greatly secured. While there are three with temporary position in which they are considered contractual nurses. It means they do not have a security of tenure. Of the five key informants, one was employed for seven years while the others worked not over than three years. But the age varies with two are older, the one is thirty years old and the other one is twenty-nine years old; they also differ in terms of job position.

\section{Research Instrument}

The researcher made use of semi-structured interview. In the interview, the researcher adopted the Bevan (2014) phenomenological structure in the interview process. It includes the description, natural attitude, modes of appearance, phenomenological reduction, and imaginative variation. The phenomenological interviewing consisted of three (3) main domains. First is the contextualization which pertains to natural attitude and life of the informants. In contextualizing questioning, it makes the informant reconstruct and describe his or her experiences in a form of narrative. The detailing of the context description allowed the informants to describe accounts of places or events, actions and activities.

The second is the apprehending the phenomenon which pertains to modes of appearing and natural attitude of the informants. This questioning focuses on the experiences of the verbally abused nurses. The researcher asked deeper questions particularly the detailed experiences with more descriptive questions. According to Bevan (2014), "the identity of an experience has modes of appearance and experience in many ways."

The third is the clarifying the phenomenon which pertains to imaginative variation and meaning of the informants lived experiences. The clarifying questioning was utilized with the use of imaginative variation in order to analyze the data gathered. Finally, the researcher asked concluding questions that explored experiences that the key informants failed to provide. This is very important in order to attain degree of completeness of the data generated from the interview.

The Bevan interview guide was validated by expert. The researcher made sure that biases and personal suppositions did not influence the data gathering.

\section{Bracketing Phase}

The interview was guided by the principle of descriptive bracketing (Chan, Fung \& Chien, 2013) which allowed the researcher to clearly set aside the base majority of personal and external suppositions, thereby focusing on the pure essences of the phenomenon. But it might not be always possible to bracket out some of the larger social and cultural elements of the world (Tufford \& Newman, 2012). The researcher realized that bracketing was quite difficult in the first key informants because the researcher shared the same sentiments on the phenomenon of verbal abuse. The researcher was not comfortable and were conscious of the ongoing interview. However, as the interview progressed, the conviction of generating the essences of the phenomenon under investigation was more interesting and challenging. Thus, the data generated from interview were rich with essences of the real experience of the key informants. 


\section{Data Gathering Procedure}

The prospective informants were contacted via mobile phones provided by the researcher's contacts. After the key informants signified their interest to take part in the study, the researcher provided them a participant information sheet. They were given a consent form and signed together with the witness. They were assured that their identity will always remain confidential and that a fictitious name will be designated to them. Confidentiality of the collected data were strictly adhered and were kept in a secured box. Only the key informants themselves and the researchers could view and edit the files of the interview.

According to Castillo-Montoya (2016), the interview is to let the respondent tell their own story on their own terms. In the interview, the key informants were asked to narrate their experiences of verbal abuses in their workplace. Open-ended questions were used in order to motivate the key informants to verbalize their personal experiences. During the interview, the researcher used English language as a medium of communication but sometimes uses the local dialect for probing questions. In the interview process, the researcher acted as an active listener and avoid interrupting the participant's narrative.

The lengths of the interviews per key informants were thirty minutes to one-hour time for interview and the interview took place in a private room where the key informants find it most convenient. The interviews were recorded on a digital recorder and were transcribed verbatim by the researcher because analysis and interpretation of such data depends on the adequacy of a carefully written manuscript. Diaries and field notes were used to add more information during the gathering of data and the non-verbal cues were also noted by the researcher.

\section{Ethical Considerations of the Study}

This research was presented to the panel of evaluators of the Cebu Normal University - College of Nursing. After getting the signal to proceed from the panel of evaluators, the researcher sent a signed transmittal letter to the Chairman of the Ethics Review Board (ERB) of Cebu Normal University together with the printed copy of the approved research paper. After the research design has been granted permit by the ERB, an endorsement to conduct the study was secured from the Dean of the College of Nursing in Cebu Normal University (Peter, 2015).

\section{DataAnalysis}

The study followed the Colaizzi seven steps of analysis with inclusion of additional step (Edward \& Welch (2011) in the analysis process. The first step was transcribing all the patients' descriptions. In this section the whole process will be based on the data, transcribe interviews, sorting, and categorizations (cool analysis) particularly on the detection of the key informant's significant statements. The extracted statement from the data transcription and the categories are then thematized (warm analysis) which include the formulation, categorization, and evolution of themes in a repertory grid or a dendogram that paved the way to discovering the value of the live experiences of nurses physically and verbally abused by patients and significant others.

The second step was extracting significant statements. This is the selection of specific explanations of each informant that have a direct link towards their lived experience of the abuses of nurses. These are then highlighted and regarded as significant. The significant statements were extracted from each of the narratives and were numerically assigned using the cardinal numbering system.

The third step was creating formulated meanings. In this stage of analysis, the researcher tries to formulate more general restatements or meanings for every significant statement extracted from the informant's narratives.

The fourth step was aggregating formulated meanings into theme clusters. The researcher allocated formulated meanings into groups which were grouped into different theme clusters.

The fifth step was developing an exhaustive description, that is, a complete explanation of the informant's experience. This was a product of the synthesis of all theme clusters and associated formulated meanings explicated by the researcher. The sixth step was an additional step, this is the researcher's interpretive analysis of symbolic representations. The seventh step was identifying the fundamental structure of the phenomenon which refers to the interpretation of the meaning of the lived experiences of nurses through a rigorous investigation of the comprehensive description of their lived experiences.

Lastly, the eighth step was a follow-up appointment that was made between the researcher and each key informant in order to validate the formulated meanings and descriptions. The meaning of their lived experiences 
must be intact despite the numerous analytic processes their statements have undergone. Furthermore, any alterations must be considered in order to maintain originality. Consequently, additional information provided by the informants are included into the final description of their lived experiences.

\section{Rigor of the Study}

According to Given (2008), there are criteria that can deliver additional standards of validity and trustworthy of the study. The rigor of the study was enhanced with the use of constant observation and permitting opportunities for short pauses towards the informants in times of prolonged engagement by the researcher.

During the interview, an audiotape and field notes containing the non-verbal cues were reviewed many times to certain the vividness and explicitness of the study with the adviser (Polit \& Beck, 2008). In order to further strengthen the credibility of the study, a member rechecked to give reaction about the analyses and obtain their feedbacks. The researcher, along with the supervision of the adviser made coding and methodical verdicts during the data analysis. Through joint decisionmaking, there is a reduction of possibility biased conclusions and idiosyncratic interpretations of the records. The strategies to ensure the rigor of this research was persistent observation, triangulation, and member checking. Thus, rigor of the study was very well established.

\section{RESULTS}

The study was able to extract a forty-three (43) significant statements with fifteen (15) formulated meanings. Three major themes emerged consequently from the extracted statements specifically: (1) destructive experience, (2) reactive responses, and (3) evasive strategies. Each theme was discussed explicitly to further direct clarification and comprehension. These lived experiences of the key informants showed the significantly expresses nurses feeling as result of verbal abuse.

\section{Theme 1: Destructive Experience}

The key informants recalled their encounters of being verbally abused. During and after the incident, they claimed that it caused them immediate harm or damage to their profession and reputation. The negative words assaulted their self-esteem and it greatly disappointed them in their profession. They felt the verbal abuse experience inflicted immense destruction among the lives of nurses because it greatly affected the way they think of themselves and the way they work with others.

Degrading experience was observed by three key informants. The key informants felt the humiliation and degradation as the abusers regard them as of little worth or of no value. They further reflected that seemingly their self-respect was lost. They realized that their dignity as a person and as a professional nurse was greatly affected. The key informants verbalized:

Ss6: "Doesn't mean you're a doctor you can look down and degrade a person especially us nurses"

SS19; "They thought nurses are just like maids that they can do anything they wish to."

SS20; "We are professionals that need to be respected too. It's just unfair and sad how people see us."

Devalued experience. The verbal abuses have caused havoc among the lives of nurses. These verbal abuses make them feel unimportant. The nurses' sense of being was greatly reduced to a point they did not find themselves significant in that work environment. Due to this devalued experience the nurses' morale were reduced (Turnbull, 2015) and they became more stressful in performing their task (Johnston et al., 2015). They expressed as:

SS21; "I feel so down as person, as a nurse and in our profession."

SS22; "I feel sad because what the significant other yelled to me was never been good to call someone like that in that moment."

SS8: "Disappointed and failed because I am a professional."

SS7; "There I realized that some patient doesn't respect us and they tend to look us down that most of the time."

Melancholy experience. The nurses who became victims of the verbal abuse felt sad and bewildered. They wander what have they done and reflect further on what trigger the verbal attack. One key informant realized that it was emotionally draining on her part and the two key informants lost interest in doing their work. The whole melancholy experience brings sadness and a wandering mind of the nurses after the verbal abuse. They said:

SS22; "I feel sad because other person yelled at me, I was never been good."

SS12; "It was more emotional draining than I thought." 
SS13; "The way they confronted me losses my selfconfidence and I lost interest in the unit."

SS14; "My moral went down because I lost my interest in the unit."

\section{Theme 2: Reactive Responses}

The key informants who experienced verbal abused were so quick to react. After every verbal abuse, the key informants responded to the aggression and other key informants tried to ignore the continuous rage coming from the victimizer. Most of the abused nurses during and after the verbal attack usually engaged in undesirable activities to manage with verbal abuse (Kisa, 2008). These activities are not really meant to counter the abusers but merely to protect themselves from the harm and shame. Thus, the reaction of the key informants from the verbal abuses were varied and unique.

Defending experience. In responding to the verbal abuse, the key informants acted upon by resisting the attack made on the abusers. They protected themselves from further harm or danger by trying to clarify the seemingly undesirable verbal attack. One key informant verbalized that she is ready to face the consequences if it means she is the culprit to cause the commotion. These actions of the key informants allowed them to simply clarify the situations and accept the mistakes in order to prevent the violent situation from making it more complicated. They said:

SS27; "Of course, I defended myself to my aggressors by just clarifying to avoid any errors from our end."

SS28; "If anything happens like if the SO file a complaint against me. I am very willing to face it. I believe what i did was right."

Seeking refuge experience. The key informants who became victims of verbal abuse felt so bad that sought someone to comfort them. They wanted psychological and emotional support from people they know and can help them. The immediate superiors were the people they clung to after the verbal abuse However, they felt frustrated and were at dismay since the superiors did not revolt to the verbal violence. This was the time the key informants needed someone to pacify her and someone to save from the abusers. But this did not happen. Out from the verbal abuse, they said:

SS29; "So we decided to report to our Head, but they didnot do anything."

SS30; "Actually nothing happened after I reported the incident to my superiors."
Countering experience. The key informants responded to hostile verbal abuses by countering the abusers. They tried to converse or discussing with the abusers in order to resolve the problem. One key informant said that calm conversation is a good way to resolve the conflict. Another key informant tried to reason well that saying bad words and shouting is not a decent way to resolve conflicts. They said:

SS31; "We come into the patient's room and spoke to the significant other that it was not a good gesture to yell and call someone a fool."

SS32; "Knowing that the situation is not that bad, and we can actually talk it out in a calm manner."

\section{Theme 3: Evasive Strategies}

The key informant's way of trying to get rid of the verbal abuses was to evade from the abusers. To get rid from the situation of verbal abuse, the key informants were able to hide the feeling of pain and sadness and by appearing differently in order to conceal their true feelings and emotions. Concealing their emotions and feelings of being hurt along with the sadness and even anger was the only way to prevent the verbal abuse from further escalation.

Ignoring experience. The verbal abuse towards the key informants leads them to respond negatively. The key informants do not acknowledge the abusers during the attack by disregarding them intentionally. One key informant did not respond to the abuser because she believed she was right and what she was doing was proper. Another key informant believed that to counter the abuser is unprofessional, so she remained reserved and went away from the abuser. They said:

SS33; "I did not give much importance to him when it happened, because I was so focus on myself.'

SS34; 'In my second experience I don't pay much attention I act as if I don't mind because there are things that we can't control so I have to be professional in dealing them.'

SS35; 'I usually tend to let it pass because I don't want it to really affect me because it would be hard to cope.'

Hold-down experience. At the time of the verbal abuse the key remain calm to control their emotions and feelings in order to prevent the escalation of the abuses. The avoidance of conflict by keeping their temper cool and isolating from the situations are the common strategies of the key informants at the time of verbal abuse. One key informant described how she held her emotion in order to prevent more conflict. They said: 
SS36; 'I am also holding my temper because I want to avoid more trouble.

SS37; 'I tend to isolate things whenever I get into those situations.'

SS38; 'I was also holding back my emotion to prevent further commotion.'

Quitting work experience. Another evasive strategy of the key informants in addressing the pain and humiliation of the verbal abuse is quitting the job. The key informants who were victims of verbal abuse firstly seek help from their superiors. But their superior and the institution did not help them instead they appeased the conflict. So they felt they are left alone to suffer the consequences of their actions. Without support from the higher authority, these nurses wanted to leave the work. They said:

SS41: "Because the management is being unfair, I decided to quit my work."

SS42: "The institution knows about it, but our head did not do anything to correct the situation, so I quit my job."

SS43: "We reported to our head but they did not do anything, so they stopped working. "

\section{DISCUSSION}

The researcher utilized a qualitative research design specifically the descriptive phenomenological approach in the conduct of the study. The research derived an indepth understanding of the lived experiences of nurses who were verbally abused in the workplace. The experiences were described by the key informants who had direct encounters and even become victims of the verbal abusers. After receiving and interpreting their stories, the phenomenon of nurse's victim of verbal abuse revealed three (3) themes which is reflective of the common experiences of nurses (see Figure 1).

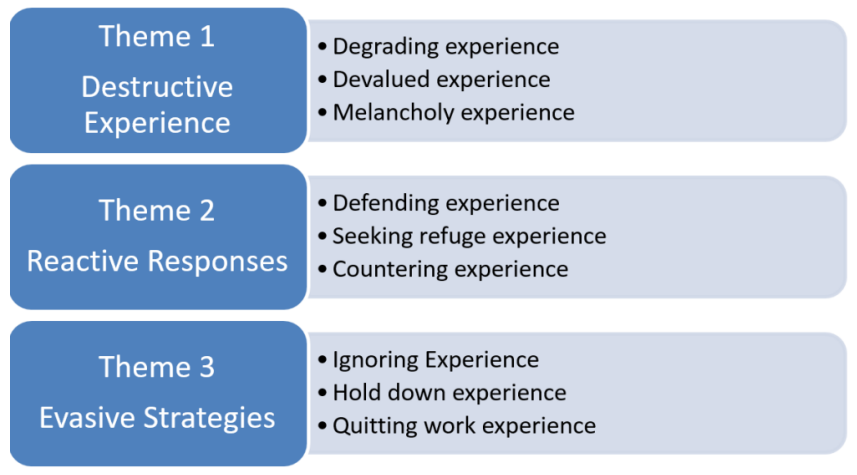

Figure 1: The Lived Experience of Nurses Verbally Abused in the Workplace
The first theme mainly describes their disturbing experiences when the verbal abuse took place. The incident of verbal abuse affects these nurses and the harm their reputation as professional nurse. The degrading experience as observed by the key informants caused shame and they felt humiliated because of the verbal attacks. They shared the experienced of being devalued because it made them think that they are not important to the lives of these abusers and their morale were reduced (Turnbull, 2015). The melancholy experience shared by these abused nurses cause made them bewildered and it seriously affected their lives. To some point, it may lead to anxiety and depression (Cromie, 2007) which may cause to have a more negative self-image (Lambert, 2014; Lykhina, 2013). According to Bordignon \& Monteiro (2016), nurses suffer anguish and emotional pain after the abuse and that would eventually lead to poor performance in their workplace.

The second theme emerge as responses showed that nurses reacted to the verbal abuses. These reactions are experienced by these nurses in order to protect themselves from further harm. The defending experience shared by these nurses made them to struggle and secure themselves from further harm and danger. By doing so, it gave space for the nurses to reflect further of the situation that happened. By seeking refuge as the nurses wanted someone to comfort them and get the support they need. Some key informants shared a countering experience as a response to the verbal abuse. They discussed with the abusers about the problem and tried to find solutions. Many nurses in the health care settings used negotiation or conflict resolution in order to help them go deal with the verbal abuses (International Council of Nurses, 2007).

The third theme reflect how nurses cope with the verbal abuse. The coping responses of the key informants is a way of evading the feeling of devalued and melancholy experiences. By evading it, the nurses hid their true feelings and emotions. The put forward a constructive approach in resolving the dreadful and depressing experiences. This response could be considered as positive even though they meant to disguise the true purpose of the study (Benjamin, 2017). The ignoring experience helped the nurses to evade the verbal abuse by paying no intention to the abusers. Streker (2012) showed that the hold-down experience reflects how nurses tried to control their feelings of being hurt and sadness in order to lessen or eliminate the seriousness of the abuses and its impact. The key informants wanted to quit the work as they felt that there was nobody to support her. As the higher authority do 
not support them and left them to face the consequences of their action (Hilton, 1989).

The use of the descriptive phenomenological approach in the study revealed three interesting themes on lived experiences of nurses who became victims of verbal abuse. These themes were not been previously explored in the context of the nursing research. In the revelation of the lived experiences of the nurses on verbal abused reflected how nurses felt regarding this phenomenon. The study also showed the nurses' response and lastly, it revealed their coping strategies. The fascinating experiences of nurses who were verbally abused has significant impact on the leadership and management approach of the nursing administrators. It can be used as a basis for planning and designing anti-violence approaches by the nursing administration of the hospitals and other related employment institutions (Pich \& Kable, 2011). However, the results of the study needed more in-depth research in order to understand the dynamics of the abuse. Further studies are needed to help Filipino nurses avoid the occurrence of verbal abuse.

\section{Implications}

The researcher noted that findings present a certain degree of stages of the nurses lived experiences on verbal abuse. The study also showed the key informant's journey through difficulties, pain and sadness, as nurses along with their capacity to resolve and cope with any violent situations. The above findings, has implications on the leaders in the workplace particularly the nurse managers. It is an eye opening for the nurse managers to be aware that being unresponsive to the call for help from junior nurses who are victims of verbal abuse, will affect the sustenance and maintenance of the nurse workforce. Moreover, the impact of the verbal abuse has an implication to the quality of work performance of nurses in the hospital setting. Nurses who are ostracized due to verbal abuse usually suffer social stigma which greatly influence their capacity to perform their task and responsibilities. Although violence in the workplace may not only address the hospital but also in other health care settings. To address the findings, it is best for the nurse leaders to adhere the current policies on violence and enforce them.

\section{RECOMMENDATIONS}

Based on the findings, the following are recommended:

1. The nurse managers and administration may explore tailor-fit approaches in the workplace for the prevention of verbal abuses.

2. To improve policies on violence in the workplace particularly in protecting nurses from verbal abuses.

3. The academician may investigate the integration of the findings to improve nursing practice.

4. The future researchers can use the findings for further studies in order to deepen the understanding of the verbal abuse among nurses.

\section{REFERENCES}

Abdou, S.A. \& El-Azeem, W.A. (2009). Verbl Abuse Against Nurses. The Medical Journal of Cairo University, 77(3), pp 335-341.

Al-Shamlan, N., Jayaseeli, N., Al-Shawi, M. \& Al-Joudi, A. (2017). Are nurses verbally abused? A cross-sectional study of nurses at a university hospital, Eastern Province, Saudi Arabia. Journal of Family and Community Medicine, 24(3), pp 173-180.

Anderson, H. (2010). Nurses experience of Workplace Violence: Towards Effective Intervention. Final Report, Work Safe BC, USA.

Benjamin, R. (2017). Uncertainty, Regret, and Psychological Pain: Why it hurts to be unsure. Thesis. The University of British Columbia, Canada. Retrieve from: https:/open.library.ubc.ca/cIRcle/collections/ubctheses/24/ items/1.0355254

Bevan, M. (2014). A Method of Phenomenological Interviewing. Qualitative Health Research. Qualitative Health Research, 24 (1), pp 136-144.

Bordignon, M. \& Monteiro, M.I. (2016). Violence in the workplace in Nursing: consequences overview. Revista Brasileira de Enfermagem, 69(5), pp 996-999.

Castillo-Montoya, M. (2016). Preparing for Interview Research: The Interview Protocol Refinement Framework. The Qualitative Report,21(5), pp 811-831. 
Chan, Z. C., Fung, Y. \& Chien, W. (2013). Bracketing in Phenomenology: Only Undertaken in the Data Collection and Analysis Process. The Qualitative Report, 18(30), pp 1-9.

Creswell, J.W. (1998). Qualitative inquiry and research design: Choosing among five traditions. $2^{\text {nd }}$ Edition, CA: Sage Publications.

Cromie, J. (2007). Verbal beatings hurt as much as sexual abuse: Can lead to depression, anxiety, and worse. Health and Medicine The Harvard Gazatte. Retrieved from: https://news.harvard.edu/gazette/story/2007/04/verbalbeatings-hurt-as-much-as-sexual-abuse/

Digal, S. (2018). Manila, 11,558 women victims of physical and sexual violence in 2017 alone. Asianews.it. Retrieved from: http://www.asianews.it/news-en/Manila,-11,558-women-victims-of-physical-and-sexual-violence-in2017-alone-43297.html

Edward, K. \& Welch, T. (2011). The extension of Colaizzi's method of phenomenological enquiry. Contemporary Nurse, 39(2), pp 163-171.

Fader, S. (2020). You're Not Crazy, But Emotional Abuse Can Make You Think You Are. Retrieved from: https://www.betterhelp.com/advice/abuse/youre-not-crazy-but-emotional-abuse-can-make-you-think-you-are/

Given, L.M. (2008). The SAGE Encyclopedia of Qualitative Research Methods. $2^{\text {nd }}$ Edition. UK: SAGE Publications, Inc. Retrieved from: http://www.yanchukvladimir.com/docs/Library/Sage\%20Encyclopedia\% 20of\%20Qualitative\%20Research\%20Methods-\%202008.pdf

Hilton, P.E. (1989). The influence of verbal abuse on intention to leave an organization among registered nurses. Theses Digitization Project. 548. Retrieved from: https://scholarworks.lib.csusb.edu/etd-project/548/?utm_source $=$ scholarworks.lib.csusb.edu\%2Fetd-project\%2F548\&utm_medium=PDF\&utm_campaign=PDFCoverPages

International Council of Nurses (2007). Guidelines on coping with violence in the workplace. International Council of Nurses, Geneva, Switzerland. Retrieved from: https:/static1.squarespace.com/ static/579770cd197 aea84455d6908/t/57d86302d1758e16f4e0f072/1473798914990/guideline_violence.pdf

Jackson, D., Hutchinson, M., Luck, L. \& Wilkes, L. (2013). Mosaic of verbal abuse experienced by nurses in their everyday work. Journal of Advanced Nursing, 69(9), pp 2066-2075.

Johnston, D., Bell, C., Jones, M., Farquharson, B., Allan, J., Schofield, P., Ricketts, I. \& Johnston, M. (2015) Stressors, Appraisal of Stressors, Experienced Stress and Cardiac Response: A Real-Time, Real-Life Investigation of Work Stress in Nurses. Annals of Behavioral Medicine, 50(2), pp 187-197.

Kisa, S. (2008). Turkish nurses' experiences of verbal abuse at work. Archives of Psychiatric Nursing, 22(4), pp 200207.

Kvak, S. (2017). Generalized Workplace Harassment and Physical Health Outcomes in Nurses in the Philippines. Dissertation M.P.H. University of Washington. USA: University of Washington Libraries.

Lambert, A. (2014). Understanding Verbal Abuse. Morningside Recovery: A Light House Property. Retrieved from: https://www.morningsiderecovery.com/addiction-blog/understanding-verbal-abuse/

Lykhina, A. (2013). Women's lived experiences of emotional and psychological abuse in heterosexual relationships: Behaviours, effects, awareness and support. Thesis. RMIT University, Australia. Retrieved from: https://researchbank.rmit.edu.au/eserv/rmit:160466/Lykhina.pdf

Manderino, M.A. \& Berkey, N. (1997). Verbal abuse of staff nurses by Physicians. Journal of Professional Nursing, 13(1), pp 48-55.

Occupational Safety and Health Administration (OSHA) (2015). Workplace Violence in Healthcare: Understanding the Challenge. Retrieved from: https://www.osha.gov/Publications/OSHA3826.pdf

Patton, M. (1990). Qualitative evaluation and research methods. Beverly Hills, CA: Sage. (pp. 169-186). Retrieved from: http://legacy.oise.utoronto.ca/research/field-centres/ross/ctl1014/Patton1990.pdf 
Peter, E. (2015). The ethics in qualitative health research: special considerations. Ciencia \& Saude Coletiva, 20(9), pp 2625-2630.

Philippine Statistic Authority (2017). Meaning of Verbal Abuse. Retrieved from: https://psa.gov.ph/content/verbalabuse

Pich, J. \& Kable, A. (2011). Patient-related violence against nursing staff working in the Emergency Department: a systematic review. A JBI Library of Systematic Reviews, 9(48), pp 1-22.

Polit, D. \& Beck, C. (2016). Nursing Research: Generating and Assessing Evidence for Nursing Practice. $10^{\text {th }}$ edition. Philadelphia: Lippincott, Williams \& Wilkins.

Qutoshi, S.B. (2018). Phenomenology: A Philosophy and Method of Inquiry. Journal of Education and Educational Development, 5(1), pp 215-222.

Streker, P.J. (2012). "I Wish That He Hit Me": The Experiences of People Who Have Been Psychoemotionally Abused and have Psychoemotionally Abused Others. Thesis, Victoria University, Australia. Retrieved from: http://vuir.vu.edu.au/19413/1/Peter_Streker.pdf

Tongco, M.D.C. (2007) Purposive Sampling as a Tool for Informant Selection. Ethnobotany Research \& Applications, 5, pp 147-158.

Tufford, L. \& Newman, P. (2012). Bracketing in qualitative research. Qualitative Social Work, 11(1), pp 80-96.

Turnbull, A. (2015). Nurses feel 'unsupported and undervalued'finds RCN. Independent Nurse: For Primary Care and Community Nurses. Retrieved from: https://www.independentnurse.co.uk/news/nurses-feel-unsupported-andundervalued-finds-ren/108048/

Varga, M. \& Holloway, S. (2014). The lived experience of the wound care nurse in caring for patients with pressure ulcers. International Wound Journal, 13(2), pp 243-51. 